\title{
Intestinal Bowel Wall Thickening Analysis on MDCT: A Retrospective Study
}

\author{
Jefrin Roy Mathew ${ }^{\circledR 1}$, A Parthasarathi ${ }^{2}$, BT Deepthi ${ }^{\circ 1}$, U Harsha ${ }^{\odot}$ \\ ${ }^{1}$ Junior Resident, Department of Radiodiagnosis, Rajarajeswari Medical College, Bangalore, Karnataka, India, ${ }^{2}$ Professor, Department of Radiodiagnosis, Rajarajeswari \\ Medical College, Bangalore, Karnataka, India.
}

\section{Abstract}

Background: The aim of this study was to determine the causes and establish the significance of bowel wall thickening on abdominal computed tomography. Subjects and Methods: Consecutive abdominal CT's between January 2019 and December 2019 with findings of duodenal, jejunal, ileal and colonic 'bowel wall thickening 'on the formal report was reviewed retrospectively. The patients history, inpatient course \& subsequent colonoscopy and /or operative findings were also reviewed. Results: Of the 88 consecutive CT abdomen's identified, infection (26.1\%) and new cancer $(22.7 \%)$ were the most common causes. Bowel obstruction (12.5\%) and Inflammatory Bowel Disease (10.2\%) were relatively uncommon causes. Overall 40/88 (45\%) \& 14/88 (15\%) patients underwent subsequent colonoscopy and progressed directly to surgery respectively; of these 36/40 (90\%) of the former and 14/14 (100\%) of the latter showed findings similar to CT. Conclusion: When thickening of the bowel is detected with CT; pattern of the thickening, accompanying findings, history of the patient and clinical features must be evaluated together to reach prompt and correct diagnosis. All cases detected with bowel wall thickening on CT abdomen should warrant a subsequent colonoscopy.

Keywords: Bowel, Thickening, Wall, Computed Tomography, Colonoscopy

Corresponding Author: Jefrin Roy Mathew, Junior Resident, Department of Radiodiagnosis, Rajarajeswari Medical College, Bangalore, Karnataka, India.

E-mail: jefrinrmathew@gmail.com

Received: 06 February 2020

Revised: 11 March 2020

\section{Introduction}

Multidetector Computed Tomography (MDCT) has become the most widely used and important imaging modality for investigating the cause of abdominal symptoms. ${ }^{[1,2]}$ It is used in the examination of patients presenting with acute abdominal complaints, known or suspected malignancy, abdominal and pelvic trauma \& inflammatory conditions. During CT interpretation of the abdomen and pelvis, the general focus is placed on the peritoneal cavity, the mesentery and the parenchymal organs. ${ }^{[3,4]}$ Bowel wall thickening is a common, non-specific finding on abdominal CT and is caused by a variety of underlying etiologies including inflammatory, infective, ischaemic and neoplastic. ${ }^{2]}$ It frequently leads to further invasive investigations including colonoscopy; however, the relevance of bowel wall thickening to the clinical presentation is many times not clear. ${ }^{[5-7]}$ There have been only a handful of studies with regard to the final causes of incidental bowel wall thickening and its correlation with subsequent endoscopic findings. Recommendations from these studies
Accepted: 30 March 2020

Published: 05 July 2020

are conflicting, with many authors suggesting high rates of underlying pathology requiring colonoscopy, while others found benign or no pathology in the majority of patients and only recommended colonoscopy in high risk patients.

\section{Subjects and Methods}

After obtaining approval from the internal ethical committee of Rajarajeswari Medical College and Hospital, Bangalore; consecutive abdominal contrast-enhanced CT's from January 2019 to December 2019 with findings of duodenal, jejunal, ileal and colonic bowel wall thickening on the formal report was reviewed. The various exclusion criteria involved were: associated wall thickening of stomach, associated wall thickening of anal canal and/or rectum, associated wall thickening of oesophagus. The equipment used was a Siemens Somatom Perspective 128 slice CT scanner. All the observations were recorded on a master sheet which included patient demographics, location of involvement, causes and subsequent interventions performed. Descriptive 
and inferential statistical analysis was done using Microsoft Excel and SPSS software.

\section{Results}

A total of 88 cases were retrospectively studied which included 56 males $(63.6 \%)$ and 32 females (36.3\%) with a mean age of 44 years. The colon alone ( 25 cases, $28.4 \%$ ) was the most common site of involvement followed by the combination of ileum and caecum (18 cases, 20.4\%). The involvement of caecum alone was the least common location of involvement (1 case, $1.1 \%)$.

\begin{tabular}{|lll|}
\hline \multicolumn{3}{l}{ Table 1: Age distribution of cases } \\
\hline Age (in years) & Number $(\mathbf{n = 8 8})$ & Percentage (\%) \\
\hline $0-20$ & 4 & 4.54 \\
$21-40$ & 37 & 42.04 \\
$41-60$ & 28 & 31.81 \\
61.80 & 19 & 21.59 \\
Mean \pm SD & $44 \pm 16.25$ & \\
\hline
\end{tabular}

Table 2: Location of involvement distribution in cases

\begin{tabular}{lll}
\hline Location & $\begin{array}{l}\text { Number } \\
(\mathbf{n = 8 8 )}\end{array}$ & Percentage (\%) \\
\hline Duodenum & 03 & 3.4 \\
\hline Jejunum & 10 & 11.3 \\
\hline Ileum & 06 & 6.8 \\
Caecum & 01 & 1.1 \\
\hline Colon & 25 & 28.4 \\
\hline $\begin{array}{l}\text { Duodenum } \\
\text { Jejunum }\end{array}$ & 02 & 2.2 \\
\hline Jejunum + Ileum & 02 & 2.2 \\
\hline Ileum + Caecum & 18 & 20.4 \\
\hline $\begin{array}{l}\text { Ileum + Caecum + } \\
\text { Colon }\end{array}$ & 13 & 14.7 \\
Caecum + Colon & 06 & 6.8 \\
\hline $\begin{array}{l}\text { Jejunum + Ileum + } \\
\text { Caecum + Colon }\end{array}$ & 02 & 2.2 \\
\hline
\end{tabular}

\section{Discussion}

Normally the small bowel wall measures between 1 to $2 \mathrm{~mm}$ when the lumen is well distended, with slight variation depending on the degree of luminal distension. Some authors have used 2-3 $\mathrm{mm}$ as the upper limit measurement of normal wall thickness of the small bowel wall and $3 \mathrm{~mm}$ as the upper limit for normal colonic wall thickness. ${ }^{[8-12]}$ The reason for bowel

\begin{tabular}{|c|c|c|}
\hline Cause & Number $(\mathrm{N}=\mathbf{8 8})$ & Percentage (\%) \\
\hline Infective & 23 & 26.13 \\
\hline $\begin{array}{l}\text { Reactive } \\
\text { Inflammatory }\end{array}$ & 08 & 09.09 \\
\hline Diverticulitis & 08 & 09.09 \\
\hline $\begin{array}{l}\text { Inflammatory } \\
\text { Bowel Disease }\end{array}$ & 08 & 09.09 \\
\hline $\begin{array}{l}\text { Bowel Obstruc- } \\
\text { tion }\end{array}$ & 10 & 11.36 \\
\hline $\begin{array}{l}\text { Ischaemic Coli- } \\
\text { tis }\end{array}$ & 06 & 06.81 \\
\hline Malignancy & 18 & 20.45 \\
\hline
\end{tabular}

\begin{tabular}{lcc}
\hline Table 4: Distribution of subsequent interventions \\
\hline $\begin{array}{c}\text { Subsequent } \\
\text { Intervention }\end{array}$ & Number $(\mathbf{N}=\mathbf{8 8})$ & Percentage (\%) \\
Colonoscopy & 40 & 45.45 \\
Progressed & 14 & 15.91 \\
Directly & To & \\
Surgery & & \\
\hline
\end{tabular}

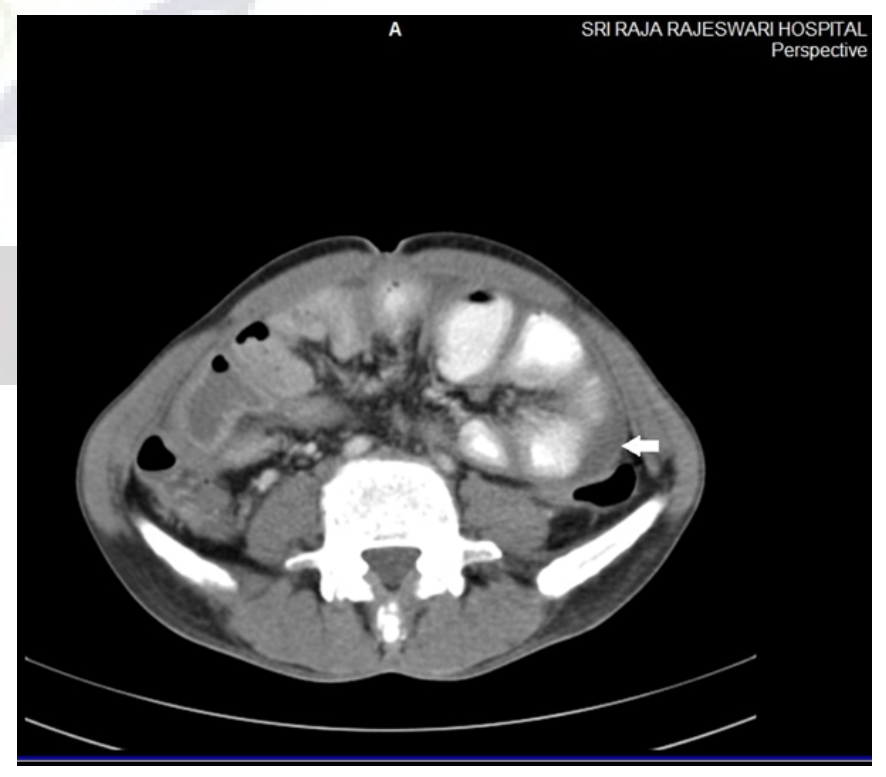

Figure 1: Case of intestinal tuberculosis showing wall thickening of the descending colon 0 .

wall thickening can be either submucosal edema, haemorrhage or neoplastic infiltration. ${ }^{[13,14]}$ The CT findings that need to be assessed while evaluating a thickened bowel include: pattern of attenuation; degree of thickening; symmetric vs assy- 


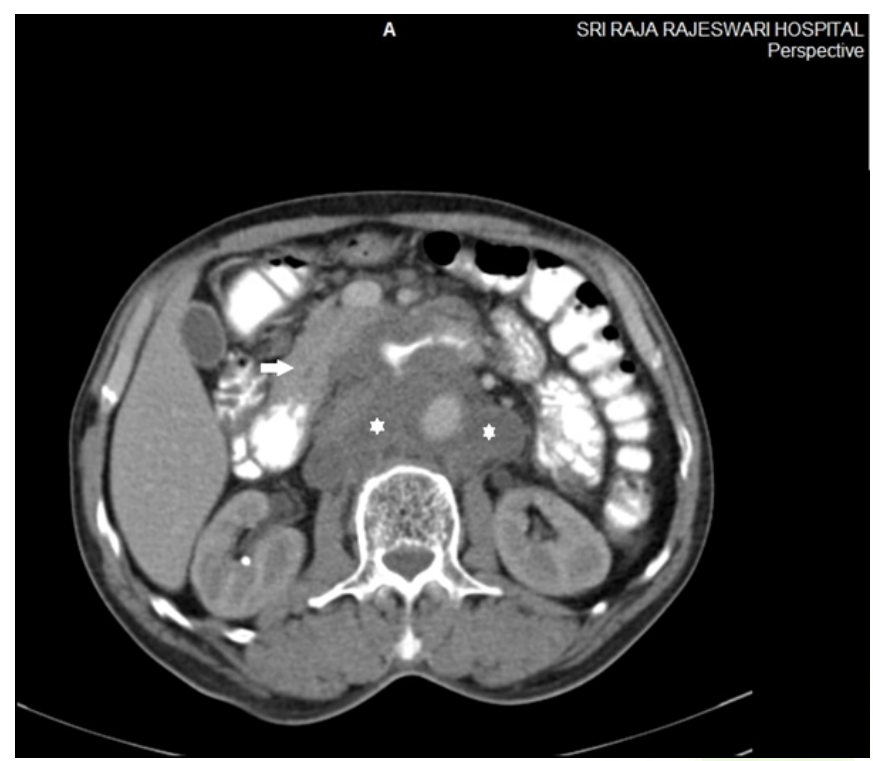

Figure 2: Case of small bowel lymphoma showing diffuse wall thickening of the jejunum () and multiple enlarged paraaortic lymphnodes (*).

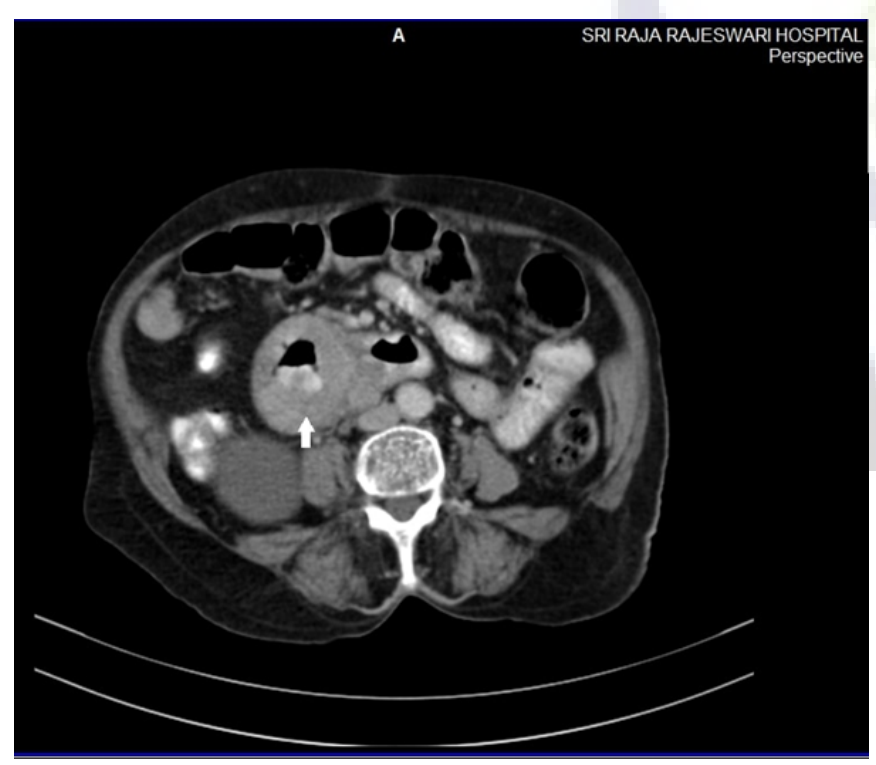

Figure 3: Case of GIST showing markedassymetric wall thickening of the duodenum ( ).

metric thickening; focal; segmental or diffuse involvement; and associated perienteric abnormalities. In addition to the above; mesenteric changes, patency of mestenteric vessels and luminal contents also need to be analysed. ${ }^{[13,15-17]}$ The various differential diagnosis on MDCT for bowel wall thickening includes collapsed bowel; if thickening is due to sub- mucosal edema as seen in conditions like Crohns, Ulcerative Colitis, Diverticulitis, Pseudomembranous colitis, Bowel ischaemia and radiation enteritis. Bowel wall thickening due to neoplastic infiltration is seen in conditions such as adenocarcinoma, lymphoma and Graft vs host disease. Other conditions such as angioedema, bowel trauma (submucosal haemorrhage), Henoch - Schonlein purpura, hypoproteinemia can also present with bowel wall thickening. ${ }^{[13,15]}$ A collapsed bowel can be differentiated from pathological bowel wall thickening by assessing other findings like mesenteric edema, vascular engorgement, lymphadenopathy and comparing nearby with distal bowel segments.

\section{Conclusion}

When thickening of bowel is detected with CT: pattern of thickening, accompanying findings, history of the patient and clinical features must be evaluated together to reach a prompt and correct diagnosis. Bowel wall thickening detected on CT can be normal variants, inflammatory conditions and gastrointestinal neoplasms. Even though none of the solitary CT findings is by itself specific, the association of several abnormal parameters will lead to a correct diagnosis or will narrow the differential diagnosis in most cases. All cases detected with bowel wall thickening on CT abdomen should warrant a subsequent colonoscopy in contrary to earlier studies recommending colonoscopy only in high risk patients.

\section{References}

1. Al-Khowaiter SS, Brahmania M, Kim E, Madden M, Harris A, Yoshida EM, et al. Clinical and Endoscopic Significance of Bowel-Wall Thickening Reported on Abdominal Computed Tomographies in Symptomatic Patients with No History of Gastrointestinal Disease. Can Assoc Radiol J. 2014;65(1):6770. Available from: https://dx.doi.org/10.1016/j.carj.2012.01. 002.

2. Ayala GP, Huang C, Jones DM, Richter S. The Significance of Correlating Incidental Bowel Wall Thickening on CT with Endoscopic Evaluation. Am J Gastroenterol. 2006;101(9):S205-S205. Available from: https://dx.doi.org/ 10.14309/00000434-200609001-00482.

3. Eskaros S, Ghevariya V, Diamond I, Anand S. Correlation of incidental colorectal wall thickening at CT compared to colonoscopy. Emerg Radiol. 2009;16(6):473-476. Available from: https://dx.doi.org/10.1007/s10140-009-0806-x.

4. Fernandes T, Oliveira MI, Castro R, Araújo B, Viamonte B, Cunha R. Bowel wall thickening at CT: simplifying the diagnosis. Insights Imaging. 2014;5(2):195-208. Available from: https://dx.doi.org/10.1007/s13244-013-0308-y.

5. Horton KM, Corl FM, Fishman EK. CT Evaluation of the Colon: Inflammatory Disease. Radiographics. 2000;20(2):399418. Available from: https://dx.doi.org/10.1148/radiographics. 20.2.g00mc15399. 
6. Modi RS, Singh H, Patel N, Matin A, Ringold DA. Bowel Wall Thickening on CT Scan Is a High Yield Colonoscopy Indication. Clin Gastroenterol Hepatol. 2012;10(3):330-331. Available from: https://dx.doi.org/10.1016/j.cgh.2011.12.011.

7. Stermer E, Lavy A, Rainis T, Goldstein O, Keren D, Zeina AR. Incidental Colorectal Computed Tomography Abnormalities: Would You Send every Patient for a Colonoscopy? Can J Gastroenterol. 2008;22(9):758-760. Available from: https://dx. doi.org/10.1155/2008/901250.

8. Thoeni RF, Cello JP. CT Imaging of Colitis. Radiology. 2006;240(3):623-638. Available from: https://dx.doi.org/10. 1148/radiol.2403050818.

9. Balthazar EJ. CT of the gastrointestinal tract: principles and interpretation. Am J Roentgenol. 1991;156(1):23-32. Available from: https://dx.doi.org/10.2214/ajr.156.1.1898566.

10. Shirkhoda A. Diagnostic pitfalls in abdominal CT. Radiographics. 1991;11(6):969-1002. Available from: https://dx.doi.org/ 10.1148/radiographics.11.6.1749860.

11. Gore RM, Balthazar EJ, Ghahremani GG, Miller FH. CT features of ulcerative colitis and Crohn's disease. Am J Roentgenol. 1996;167(1):3-15. Available from: https://dx.doi. org/10.2214/ajr.167.1.8659415.

12. James S, Balfe DM, Lee JK, Picus D. Small-bowel disease: categorization by CT examination. Am J Roentgenol. 1987;148(5):863-868. Available from: https://dx.doi.org/10. 2214/ajr.148.5.863.

13. Scanlon MH, Blumberg ML, Ostrum BJ. Computed tomographic recognition of gastrointestinal pathology. Radiographics. 1983;3(2):201-227. Available from: https://dx.doi.org/10. 1148/radiographics.3.2.201.

14. Karahan OI, Dodd GD, Chintapalli KN, Rhim H, Chopra S. Gastrointestinal Wall Thickening in Patients with Cirrhosis:
Frequency and Patterns at Contrast-enhanced CT. Radiology. 2000;215(1):103-107. Available from: https://dx.doi.org/10. 1148/radiology.215.1.r00ap30103.

15. Horton KM, Corl FM, Fishman EK. CT Evaluation of the Colon: Inflammatory Disease. Radiographics. 2000;20(2):399418. Available from: https://dx.doi.org/10.1148/radiographics. 20.2.g00mc15399.

16. Lane MJ, Katz DS, Mindelzun RE, Jeffrey RB. Spontaneous intramural small bowel haemorrhage: Importance of noncontrast CT. Clin Radiol. 1997;52(5):378-380. Available from: https://dx.doi.org/10.1016/s0009-9260(97)80133-x.

17. Balthazar EJ, Hulnick D, Megibow AJ, Opulencia JF. Computed Tomography of Intramural Intestinal Hemorrhage and Bowel Ischemia. JCAT. 1987;11(1):67-72. Available from: https://dx.doi.org/10.1097/00004728-198701000-00013.

Copyright: (C) the author(s), 2020. It is an open-access article distributed under the terms of the Creative Commons Attribution License (CC BY 4.0), which permits authors to retain ownership of the copyright for their content, and allow anyone to download, reuse, reprint, modify, distribute and/or copy the content as long as the original authors and source are cited.

How to cite this article: Mathew JR, Parthasarathi A, Deepthi BT, Harsha U. Intestinal Bowel Wall Thickening Analysis on MDCT: A Retrospective Study. Asian J. Med. Radiol. Res. 2020; 8(1):106-109.

DOI: dx.doi.org/10.47009/ajmrr.2020.8.1.19

Source of Support: Nil, Conflict of Interest: None declared.

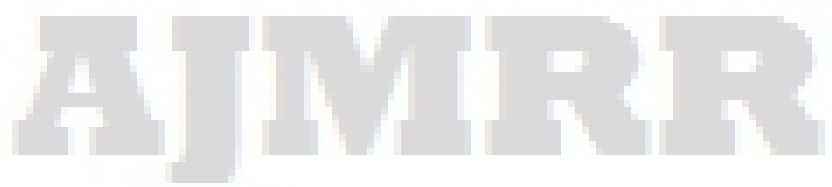

